\title{
Literature review and suggested protocol for prevention and treatment of corneal graft rejection
}

\author{
Otavio Azevedo Magalhaes ${ }^{1} \cdot$ Ahmed Shalaby Bardan ${ }^{2,3} \cdot$ Mehran Zarei-Ghanavati $^{4} \cdot$ Christopher Liu $^{2,5}$
}

Received: 9 August 2018 / Revised: 12 May 2019 / Accepted: 20 May 2019 / Published online: 22 July 2019

(c) The Author(s), under exclusive licence to The Royal College of Ophthalmologists 2019

\begin{abstract}
Effective prophylaxis and treatment of corneal graft rejection are essential to improve outcomes in corneal transplantation. To date, there has been no standardized protocol published that outlines the optimal prophylactic and therapeutic approaches and, furthermore, the published controlled trials on this subject are limited. Likewise, no study has addressed how the level of antigen exposure varies between different types of keratoplasties. The aim of this paper is to provide a simple evidencebased protocol for the prevention and treatment of corneal graft rejection.
\end{abstract}

\section{Introduction}

Although corneal grafting is considered the most common and successful tissue transplantation procedure in medicine, there is no standardized protocol for postoperative prophylaxis and treatment of immunological rejection to date. The majority of corneal grafts occur as first transplants in low-risk recipients such as those with keratoconus and dystrophies (5-year survival rate of over $90 \%$ with only topical immunosuppression); others occur in high-risk hosts [1]. These include: eyes with two or more quadrants of vascularization; recipient graft trephination over $8.25 \mathrm{~mm}$, Herpes simplex keratitis (HSK); uveitis; silicone oil keratopathy; previously failed (rejected) grafts; infected "hot eyes"; and young recipient age [2]. Previous surgeries, particularly glaucoma, anterior iris synechiae, and vitreous adhesions all raise the rejection risk of the transplanted graft. Despite advances in antiinflammatory therapy, glaucoma management, surgical techniques, and postoperative

$\triangle$ Otavio Azevedo Magalhaes

otaviomaga@yahoo.com.br

1 Porto Alegre Eye Bank Hospital, Porto Alegre, Brazil

2 Sussex Eye Hospital, Brighton, England

3 Faculty of Medicine, Alexandria University, Alexandria, Egypt

4 Eye Research Center, Farabi Eye Hospital, Tehran University of Medical Sciences, Tehran, Iran

5 Tongdean Eye Clinic, Hove, England care rejection rates remain high in this group of high-risk patients (over 60\%) [1,3].

Topical corticosteroids are the most common medication prescribed to prevent immunologic rejection after keratoplasty, but there are important differences in the postoperative management protocols [3-6]. Although weaker steroids may have better safety profiles, some patients will require the strongest available drug to control their inflammation [5-8]. The most widely prescribed topical corticosteroid in the world is prednisolone acetate $1 \%$ [6]. Not all medications are available worldwide, for example, the high-potency steroid difluprednate (Durezol $^{\mathrm{TM}}$, Alcon Laboratories Inc., Fort Worth, TX, USA) [8].

Ophthalmologists have achieved important advances in transplantation techniques and image technology over the past several decades [9-12]. However, the postoperative protocols published to date do not take into consideration the different types of keratoplasty $[5,13]$. This review aims to establish a simple prophylactic postoperative protocol for corneal transplantation and graft rejection treatment based on the current literature.

\section{Methods}

An observational retrospective literature search using MEDLINE's database was performed on randomized clinical trials (RCTs), corneal transplantation, and postoperative management. We included only English language studies. No date restriction was applied. The keywords searched 
were: corneal transplantation, corneal rejection, rejection treatment, and rejection prophylaxis.

\section{Graft rejection prophylaxis}

\section{Penetrating keratoplasty (PK)}

\section{Steroids}

Topical prednisolone acetate $1 \%$ or dexamethasone sodium phosphate $0.1 \%$ every 2,3 , or $4 \mathrm{~h}$ initially is then slowly reduced over a period of 6-12 months but maintained once daily indefinitely; this constitutes the routine immediate postoperative prophylaxis against endothelial graft rejection in PK $[5,14,15]$. Prednisolone acetate $1 \%$ achieves high aqueous levels within $120 \mathrm{~min}$ and maintains a significant level over $24 \mathrm{~h}$, whereas dexamethasone $0.1 \%$ attains peak aqueous levels (20 times lower than prednisolone) within $90 \mathrm{~min}$, and detectable levels are seen at $12 \mathrm{~h}$ [16]. Table 1 details the potencies of the currently available topical steroids [17-21].

Fluorometholone and loteprednol etabonate ophthalmic suspension were used by $\sim 10 \%$ of respondents in the 2011 Cornea Society questionnaire for the low-risk immediate postoperative period but rarely for high-risk grafts [5]. Difluprednate has become widely used in the treatment of postoperative inflammation [9]. Shimazaki and colleagues reported that prolonged use of fluorometholone $0.1 \%$ could be beneficial for the prevention of graft rejection after low-risk PK [19], as no adverse consequences were seen in this trial. Therefore, continued use of low-dose corticosteroids once daily indefinitely, even in non-high-risk cases is recommended [22]. Immediate postoperative subconjunctival injections of methylprednisolone acetate $40 \mathrm{mg} / \mathrm{mL}$ or dexamethasone disodium phosphate $0.1 \%$ for routine prophylactic management of graft rejection has also been reported by several corneal specialists in the 2004 survey [3]. This management routine is used by $54 \%$ of corneal surgeons in high-risk cases. In these cases, subconjunctival corticosteroids can be used to provide high concentrations in liquefied aqueous solutions, which maintain better immunosuppression for longer periods of time [23]. Regarding safety, it has been shown that the time required for complete epithelial healing did not differ significantly in patients who received subconjunctival steroids compared to those who did not [24].

In a previous survey of Castroviejo Cornea Society members, systemic steroids were the therapeutic of choice post-keratoplasty of only $7 \%$ in low-risk cases and $23 \%$ in high-risk cases [25]. No study has shown the advantage of this practice.

\section{Cyclosporine}

Topical ophthalmic cyclosporine A (CsA) has been prescribed for some years and has gained popularity for treating dry eye, as well as prophylactically in high-risk corneal graft, although its efficacy is still debatable for the latter. The concentration of the drug for this purpose varies from 0.05 to $2 \%$ in the literature. In high-risk corneal grafts, the efficacy of topical CsA $0.05 \%$ combined with topical dexamethasone was not better than that of dexamethasone alone in preventing rejection [26]. Similarly, the use of commercially available CsA $0.05 \%$ as an adjunct to topical steroids did not improve the outcome of PK rejection treatment [27]. There was no statistically significant difference in the incidence of graft rejection between topical CsA 2\% and the control group in high-risk cases. However, reversal of rejection episodes was seen in a greater number of eyes in the study group [28]. Interesting, $48 \%$ of respondents in the 2004 Cornea Society survey recommended topical CsA for postoperative management of highrisk grafts. The efficacy of oral CsA on prevention of corneal allograft rejection is questionable. Several studies have observed controversial outcomes regarding rejection prophylaxis. In one of the few RCTs, the authors found no statistically significant difference in the rates of rejection or failure between the systemic CsA-treated group and controls [29]. The conclusion is that systemic side effects limit the use of this medication. High-dose subconjunctival CsA implants did not affect corneal neovascularization after high-risk PK, providing minimal antiangiogenic effects in the transplant setting [30].
Table 1 Topical Steroids Potencies

\begin{tabular}{llll}
\hline Topical steroids drops & Antiinflammatory potency & Penetration & $\begin{array}{l}\text { Effect } \\
\text { on IOP* }\end{array}$ \\
\hline Fluorometholone acetate $0.1 \%[17]$ & Moderate & Low & Low \\
Loteprednol etabonate $0.5 \%[18]$ & High & Low & Low \\
Dexamethasone phosphate 0.1\% [19] & High & Moderate & High \\
Prednisolone acetate 1\% [20] & High & High & High \\
Difluprednate $0.05 \%[21]$ & Very high & High & Very high \\
\hline
\end{tabular}

*IOP intraocular pressure 


\section{Tacrolimus}

Topical tacrolimus (FK506) penetrates the cornea and is efficacious for preventing corneal graft rejection in animal models [31]. A retrospective study has been published comparing topical prednisolone $1 \%$ alone to prednisolone $1 \%$, combined with topical tacrolimus $0.03 \%$ (oil ophthalmic solutions) in patients with highrisk transplants. The authors found that the tacrolimus adjuvant group had a lower rate of irreversible graft rejection (secondary failure) than the prednisolone-alone group [32]. Other formulations of FK506, such as the $0.02 \%$ aqueous suspension or ointment, require further investigation as a potential treatment in high-risk corneal grafts. Oral tacrolimus was described as an effective modality to prevent allograft rejection for high-risk corneal transplantation [33]. Remarkably fewer graft rejection episodes and longer graft survival periods were observed with oral tacrolimus than with CsA. However, $20 \%$ of patients on tacrolimus had their treatment discontinued due to its toxicity.

\section{Biologics}

Few studies demonstrated that off-label subconjunctival bevacizumab reduces the amount of neovascularization and helps to increase the frequency of graft survival in cases of high-risk corneal transplants [34]. When used in combination with topical bevacizumab, the prophylaxis is more effective [35] but, at $2.5 \%$ alone four times daily for 24 weeks, it was even less effective [36]. The ranibizumab humanized anti-VEGF Fab antibody combines modulation of hemangiogenesis and lymphangiogenesis by vascular endothelial growth factor (VEGF)-Trap R1R2 after average-risk corneal transplantation and has recently been shown to improve graft survival in a murine model but no study has been performed in humans [37]. We identified an unpublished trial (clinicaltrials.gov-NCT01072357) comparing a one-time subconjunctival injection of $0.1 \mathrm{~mL}(2.5 \mathrm{mg})$ bevacizumab followed by topical treatment with $1 \%$ solution bevacizumab four times per day for 4 weeks to placebo ( $\mathrm{NaCl} 0.9 \%$ injection plus eye drops). Another biological agent, basiliximab, is a chimeric monoclonal antibody directed against the $\alpha$ chain of the IL-2R (also known as CD25) found on the surface of activated $T$ cells. This systemic agent had lower efficacy in preventing immune reactions after high-risk keratoplasty than CsA [38]. However, the side effect profile of basiliximab is more favorable than that of CsA. Preliminary data suggest that a combination therapy of basiliximab and CsA is promising. Further evaluation in a prospective multicentre study is needed.

\section{Mycophenolate mofetil (MMF)}

MMF has been used in the treatment of posterior uveitis and high-risk corneal transplantation. In a retrospective study comparing CsA and MMF in high-risk corneal transplantation, there was no statistical difference in terms of rejection episodes, graft survival, and occurrence of adverse events during a follow-up of 3 years [39]. Reis et al. reported a significantly greater effect of MMF in preventing graft rejection compared to CsA after this period but found no obvious difference in terms of graft survival. In terms of safety, MMF-treated patients had fewer side effects than CsA-treated patients [40].

\section{Rapamycin}

Clinical studies failed to demonstrate the efficacy of rapamycin (rapa) when used as a monotherapy. Systemic treatment with rapa alone or in combination with CsA was evaluated in a high-risk corneal allograft murine model. Combined treatment with low-dose CsA and rapa resulted in superior graft survival and effectively modulated the mRNA expression of inflammation markers [41]. Six high-risk patients used rapa and MMF for 1 year followed by 2 years of rapa monotherapy [42]. Only one irreversible rejection occurred. Rapa prophylaxis is known for its adverse effects. Amongst these are metabolic defects that include hyperglycemia, hyperlipidemia, arterial thrombosis, insulin resistance, and increased incidence of new-onset type 2 diabetes.

\section{Azathioprine (Aza)}

We found only one study, with a limited number of participants, on the systemic use of Aza [43]. Triple therapy with Aza, oral prednisone, and CsA was used successfully in three high-risk corneal transplant patients prior to regrafting. There are insufficient data concerning the use of Aza for corneal rejection prevention.

\section{Cyclophosphamide}

Low-dose intravenous cyclophosphamide has not yet been studied for corneal transplantation treatment or prophylaxis. The major limitations preventing the use of this alkylating agent are its frequent side effects. It has been cited as a treatment for severe ocular inflammation and mucous membrane pemphigoid in noncomparative case studies [44, 45].

\section{Deep anterior lamellar keratoplasty (DALK)}

The past decade has seen a wide adoption of lamellar transplant procedures [46]. Advantages of partial-thickness procedures include improved short- and long-term visual 
outcomes, graft survival, reduced astigmatism, and fewer suture complications compared to PK [47, 48]. Although DALK eradicates the risk of endothelial rejection, some corneal surgeons mistakenly assume that a short corticosteroid regimen is adequate. However, stromal and epithelial graft rejection, although less common, can still occur in DALK [49]. Several studies reported substantial rates of stromal rejection after DALK in the first postoperative year $[50,51]$. A retrospective study showed that stromal rejection initially occurs in the first 12 months after surgery and is characterized by acute stromal edema and/or peripheral vascularization (sometimes accompanied by epithelial edema); this responds well to topical corticosteroids [52]. Likewise, late stromal rejection after DALK provided clinical evidence that donor keratinocytes may persist in lamellar grafts for extended periods and patients should be warned that rejection may occur even many years after surgery [51].

We found 167 keratoconic DALK cases in Southern Brazil [53]. The graft failure rate was $\sim 6 \%$ over 3 years. These numbers are higher than in other studies $[49,54]$. In these two institutions, prednisolone $1 \%$ is usually tapered over 6 months postoperatively in low-risk patients. In a retrospective study with 251 individuals, dexamethasone and neomycin ophthalmic ointment were prescribed four times daily for the first week (off-label use). Prednisolone acetate $1 \%$ ophthalmic solution was tapered by one drop per week for a total of $\sim 7$ postoperative weeks. Approximately $10 \%$ of these grafted patients had rejection episodes after following this regimen [50]. Therefore, we believe these rejection numbers are too high for a lamellar procedure and it is prudent to maintain DALK patients on topical corticosteroids at least once daily for the first 12 postoperative months. In specific cases, such as atopics and vascularized beds, patients may benefit from the prolonged use of topical corticosteroids (Fig. 1) [51].

\section{Descemet stripping automated endothelial keratoplasty (DSAEK)}

Only a few years ago, DSAEK was the most common partial-thickness procedure performed at different cornea centers. DMEK is now the most commonly performed corneal graft surgery worldwide $[55,56]$. DSAEK results in significantly better 5-year graft survival rates compared with PK in patients with Fuchs endothelial corneal dystrophy and bullous keratopathy [57]. This could be explained by the lack of epithelial or subepithelial rejection. Also, there is no need for corneal sutures in DSAEK. However, several studies have shown that immunological rejection is a significant risk after DSAEK, as it is after low-risk PK [58, 59].
In a prospective study with $>600$ DSAEK eyes, the majority of graft rejections occurred 12 months postoperatively, with the greatest number of rejections occurring between postoperative months 12 and 18 [57]. This corresponds with the usual postoperative regimen of stopping steroid drops 1 year after surgery to prevent steroid-induced complications, such as steroid-induced glaucoma or cataract formation [59]. Given the increased graft rejection episodes during this period and the negative effect of such episodes on endothelial cell loss, it may be prudent to continue topical steroid eye drops indefinitely unless there is a reason to discontinue them. Switching patients from prednisolone acetate $1 \%$ to either loteprednol or fluorometholone at postoperative year one may be a better option for many patients to decrease the risk of graft rejection compared to complete discontinuation. From a retrospective study with 400 subjects, after 1 year, $50 \%$ of the patients who experienced rejection were not using topical steroids when the rejection occurred. Cessation of topical corticosteroids was associated with an odds ratio of 6.25 for developing graft rejection [60]. Thus, if the eye is not phakic or experiencing steroid-responsive glaucoma, once-daily steroid drops should be continued indefinitely after DSAEK (Fig. 1).

\section{Descemet membrane endothelial keratoplasty (DMEK)}

Lamellar transplants have quantitatively less alloantigen than full-thickness donor corneas and are expected to have higher rates of survival. These patients have a lower risk of immunologic and allorecognition rejection. Compared with other keratoplasty types, DMEK offers great advantages such as rapid visual recovery, better quality of vision, and a lower risk of immunologic rejection (15-fold lower) [9]. Reported rejection rates are $1 \%$ or less in the first 2 years after DMEK [9]. In a retrospective case series, the rate of rejection episodes was $0 \%$ in the prednisone group and $1.4 \%$ in the fluorometholone group, which is in line with other previously reported studies using both medications [61]. However, no statistically significant difference between these two was observed. A recent study with loteprednol etabonate $0.5 \%$ gel and prednisolone acetate $1 \%$ ophthalmic suspension showed that both medications successfully prevented graft rejection in the first year after DMEK [62]. In addition, the risk of intraocular pressure (IOP) elevation was significantly less with loteprednol etabonate.

We believe that DMEK patients should continue using a weak topical steroid once daily indefinitely, especially in pseudophakic and controlled patients with IOP. About 6\% of patients who stopped topical steroids after 1 year had a rejection episode during the next year [63]. Routine examinations should be performed, especially if steroids are discontinued, as rejection episodes were asymptomatic in most of the reported cases (Fig. 1). 


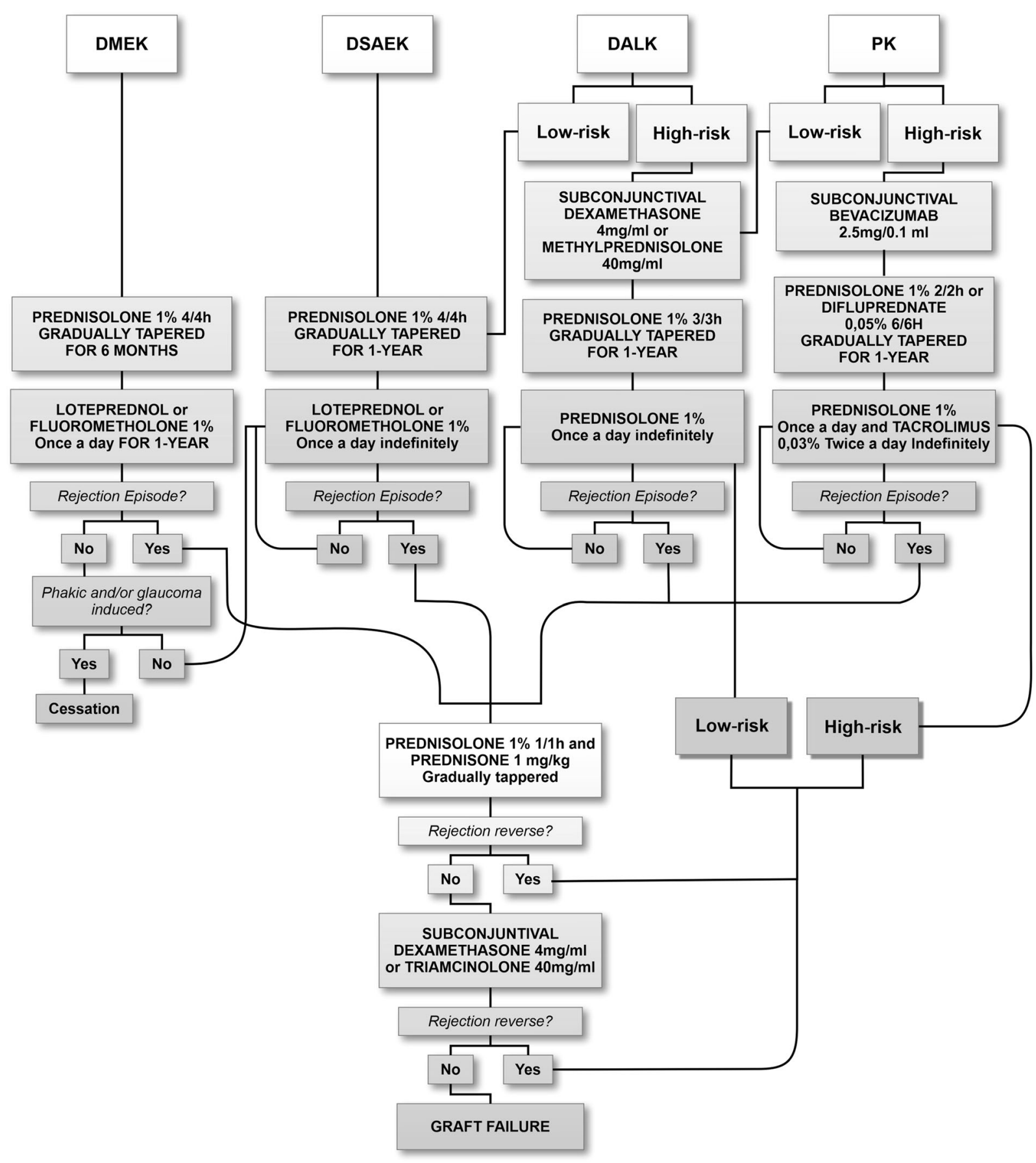

Fig. 1 Corneal transplantation management protocol

\section{Acute rejection treatment}

The practice patterns consist of starting topical prednisolone acetate $1 \%$ every hour and systemic oral prednisone $1 \mathrm{mg} /$ $\mathrm{kg}$ usually tapered over $6-8$ weeks $[2,22,64]$. Unfortunately, oral prednisolone has only been described in a few reports [22]. Intravitreal implant of dexamethasone can be used for the treatment of corneal graft rejection in cases that are refractory to standard topical and systemic therapy [23]. However, no RCT has been performed to assess the efficacy of this therapy. Intravenous methylprednisolone has been used for the treatment of endothelial graft rejection for over 30 years $[65,66]$. An RCT compared one intravenous pulse of methylprednisolone $500 \mathrm{mg}$ in addition to local corticosteroid treatment, to a local treatment regimen only. The local treatment standardized in all cases for the first $24 \mathrm{~h}$ 
consisted of one subconjunctival betamethasone $2 \mathrm{mg}$ injection and dexamethasone $0.1 \%$ drops in the affected eye every hour for $24 \mathrm{~h}$. No statistically significant difference was found between the two groups in terms of reversal of the graft rejection episode, later recurrence of graft rejection, or graft failure [67]. Effectiveness of treating corneal endothelial rejection in PK with a subconjunctival injection of triamcinolone acetonide $20 \mathrm{mg}$, in combination with the topical application of prednisolone acetate $1 \%$, was also superior to an intravenous pulse of $500 \mathrm{mg}$ methylprednisolone with topical application of prednisolone acetate $1 \%$ [55]. Subconjunctival triamcinolone yielded clearer grafts 1 year after corneal rejection, similar to excellent results described in the literature. Patients with glaucoma should have their IOP monitored, as the triamcinolone-treated group had more secondary glaucoma compared to the control group [68]. Another recent RCT compared topical and oral steroids with and without adjuvant topical tacrolimus $0.05 \%$ [69]. This study did not find a significant difference in the rejection reversal rate between the two treatment groups [70]. Likewise, no beneficial effects of topical CsA $0.5 \%$ and $0.05 \%$ eye drops in the treatment of corneal graft rejection were observed in two studies [5, 71]. We agree with the authors that oral and topical steroid therapies are intense and leave little room for an adjunct agent to play a major role. Intracameral dexamethasone and triamcinolone have only been assessed as adjunctive measures in pilot studies of patients with endothelial immune reactions after PK. Side-effects of intracameral steroid injection could have potentially occurred, such as intraocular infection or cataract formation [72, 73].

\section{Discussion}

The review of the literature for the prevention and treatment of allograft rejection reveals a significant paucity in RCT. Nevertheless we have been able to prepare a working protocol based on current literature for all graft subtypes. Establishing the risk factors for each type of keratoplasty is the first step toward preventing immunological rejection, such as deep stromal vascularization, previous history of a rejected graft in the operated or fellow eye, atopy, HSK, and uncontrolled IOP. Herpetic recurrences are thought to be triggered by systemic immunosuppression. However, prospective studies suggest that immunosuppressive treatment did not cause herpetic recurrences as long as $800 \mathrm{mg}$ of oral acyclovir was administered daily for at least 1 year [74, 75]. In addition, most herpetic recurrences were observed after termination of the immunosuppressive therapy and the simultaneous prophylactic treatment with acyclovir [76]. Is it questionable whether systemic acyclovir may not able to prevent recurrences, but it may prolong the recurrence-free interval and eventually reduce the duration of herpetic disease outbreak [77].

Topical corticosteroids remain the mainstay to prevent immunological graft reactions for all types of corneal transplants. Long-term prednisolone acetate $1 \%$ was chosen instead of dexamethasone because of its greater ocular penetration and effective immunosuppression even through an intact epithelium in PK, high-risk DALK and after rejection episode resolution [78]. Furthermore, prolonged use of fluorometholone acetate $0.1 \%$ and loteprednol etabonate $0.5 \%$ were effective for the prevention of rejection after keratoplasty. As no adverse consequences were noted, low-dose corticosteroids use has been recommended for low-risk cases, such as DSAEK and DALK [16].

The use of newer agents, such as difluprednate, is expanding. In contrast, systemic immunosuppressants provide questionable improvements in graft survival [43]. There is currently no consensus on which regimen is most efficacious for individual cases of high-risk corneal transplantation [79]. Immunosuppressive regimens showed a shift from studies using oral CsA to later studies using drugs combinations, such as MMF and tacrolimus [40, 80]. No remarkable differences in either the rejection or graft clarity rate between eyes with and without CsA therapy were observed in a RCT [29]. The relatively high incidence of systemic side effects observed with CsA administration indicates that this drug should not be recommended for use in corneal transplant recipients $[29,40]$. Tacrolimus and MMF together has been shown to be more effective and safer than CsA in decreasing risk of rejection in keratolimbal allograft with high-risk PK $[80,81]$. However, their routine administration is not advised. Long-term systemic immunosuppression would benefit from close collaboration between ophthalmologists and transplant specialists to individualize treatments. Also, to improve the prognosis for high-risk corneal transplantation, different approaches, such as the use of keratoprosthesis, may be required.

Topical CsA efficacy toward reducing the risk of rejection in high-risk transplantations is questionable, while topical tacrolimus has shown promising results in retrospective studies. Several formulations and concentrations of tacrolimus used in clinical practice have been described (ranging from 0.01 to $0.1 \%$ ). However, the majority is not synthesized to be marketed. Thus, hospital pharmacy departments and compounding pharmacies are responsible for its formulation as a sterile pharmaceutical compound for clinical use worldwide, which limits their availability. Tacrolimus ointment 0.03 and $0.1 \%$ (Protopic ${ }^{\circ}$ ) is commercially available for the treatment of atopic dermatitis. RCTs are still needed to determine ideal prophylactic regimens.

Preoperative preparation for transplants is also a subject of debate. In high-risk cases, bevacizumab was recently 
reported to reduce neovascularization, thereby prolonging graft survival $[35,36]$. Despite approval by the US Food and Drug Administration in 2008 for the treatment of the inflammation and pain associated with ocular surgery, difluprednate ophthalmic emulsion is not commercially available in Latin America, Asia, and many countries of the European Union. When it becomes available, we believe that this drug could be the steroid of choice in highrisk cases.

Patient understanding remains a serious concern and ophthalmologists should encourage self-care and compliance. Many rejection episodes are detected during the routine examination of asymptomatic patients, suggesting that regular examination of patients with all types of grafts is important to help maintain transparency. We strongly believe it is prudent to treat any questionable edema in a corneal graft with corticosteroids. In patients with herpetic keratitis, systemic acyclovir treatment must be promptly introduced. Considerable IOP elevation can even occur with once-daily dosing of prednisolone, so patients should have that checked regularly to reduce the risk of optic nerve damage [2]. The benefit of long-term steroid eye drops must be weighed against the risks of individualized criteria. Pharmaceutical and technological developments will enable the creation of potent topical drugs with higher penetration, better bioavailability, rapid local metabolism, and stronger efficacy with lower incidences of local and systemic adverse effects.

This review summarizes and informs future corneal transplant rejection prevention and management strategies based on the most current evidence available. The individual regimens practised by different corneal surgeons vary widely in terms of rejection management preferences. It is important to acknowledge that the amount of exposed antigen is different in DMEK and vascularized PK. Thus, different strategies are needed to improve the transplantation survival rate.

\section{Compliance with ethical standards}

Conflict of interest The authors declare that they have no conflict of interest.

Publisher's note: Springer Nature remains neutral with regard to jurisdictional claims in published maps and institutional affiliations.

\section{References}

1. Patel NP, Kim T, Rapuano CJ, Cohen EJ, Laibson PR. Indications for and outcomes of repeat penetrating keratoplasty, 1989-1995. Ophthalmology. 2000;107:719-24.

2. Randleman JB, Stulting RD. Prevention and treatment of corneal graft rejection: current practice patterns (2004). Cornea. 2006;25: 286-90.
3. Pineda R. Corneal transplantation in the developing world: lessons learned and meeting the challenge. Cornea. 2015;34:35-40.

4. Kharod-Dholakia B, Randleman JB, Bromley JG, Stulting RD. Prevention and treatment of corneal graft rejection: current practice patterns of the Cornea Society (2011). Cornea. 2015;34: 609-14.

5. Poon A, Constantinou M, Lamoureux E, Taylor HR. Topical cyclosporin $\mathrm{A}$ in the treatment of acute graft rejection: a randomized controlled trial. Clin Exp Ophthalmol. 2008;36:415-21.

6. Sinha R, Jhanji V, Verma K, Sharma N, Biswas NR, Vajpayee RB. Efficacy of topical cyclosporine A $2 \%$ in prevention of graft rejection in high-risk keratoplasty: a randomized controlled trial. Graefes Arch Clin Exp Ophthalmol. 2010;248:1167-72.

7. Dhaliwal JS, Mason BF, Kaufman SC. Long-term use of topical tacrolimus (FK506) in high-risk penetrating keratoplasty. Cornea. 2008;27:488-93.

8. Jamal KN, Callanan DG. The role of difluprednate ophthalmic emulsion in clinical practice. Clin Ophthalmol. 2009;3:381-90.

9. Anshu A, Price MO, Price FW. Risk of corneal transplant rejection significantly reduced with Descemet's membrane endothelial keratoplasty. Ophthalmol. 2012;119:536-40.

10. Olson EA, Tu EY, Basti S. Stromal rejection following deep anterior lamellar keratoplasty: implications for postoperative care. Cornea. 2012;31:969-73.

11. Belin MW, Villavicencio OF, Ambrosio RJR. Tomographic parameters for the detection of keratoconus: suggestions for screening and treatment parameters. Eye Contact lens. 2014;40: 326-30.

12. Koay PY, Lee WH, Figueiredo FC. Opinions on risk factors and management of corneal graft rejection in the United Kingdom. Cornea. 2005;24:292-6.

13. Price FW Jr, Price DA, Ngakeng V, Price MO. Survey of steroid usage patterns during and after low-risk penetrating keratoplasty. Cornea. 2009;28:865-70.

14. Diederich S, Scholz T, Eigendorff E, Bumke-Vogt Ch, Quinkler M, Exner P, et al. Pharmacodynamics and pharmacokinetics of synthetic mineralocorticoids and glucocorticoids: receptor transactivation and prereceptor metabolism by 11 beta-hydroxysteroiddehydrogenases. Horm Metab Res. 2004;36:423-9.

15. Awan MA, Agarwal PK, Watson DG, McGhee CN, Dutton GN. Penetration of topical and subconjunctival corticosteroids into human aqueous humour and its therapeutic significance. $\mathrm{Br} \mathrm{J}$ Ophthalmol. 2009;93:708-13.

16. Shimazaki J, Iseda A, Satake Y, Shimazaki-Den S. Efficacy and safety of long-term corticosteroid eye drops after penetrating keratoplasty: a prospective, randomized, clinical trial. Ophthalmology. 2012;119:668-73.

17. Kupferman A, Berrospi AR, Leibowitz HM. Fluorometholone acetate. A new ophthalmic derivative of fluorometholone. Arch Ophthalmol. 1982;100:640-1.

18. Comstock TL, Sheppard JD. Loteprednol etabonate for inflammatory conditions of the anterior segment of the eye: twenty years of clinical experience with a retrometabolically designed corticosteroid. Expert Opin Pharm. 2018;19:337-53.

19. Weijtens O, Schoemaker RC, Romijn FP, Cohen AF, Lentjes EG, van Meurs JC. Intraocular penetration and systemic absorption after topical application of dexamethasone disodium phosphate. Ophthalmol. 2002;109:1887-91.

20. McGhee CN, Noble MJ, Watson DG, Dutton GN, Fern AI, Healey TM, et al. Penetration of topically applied prednisolone sodium phosphate into human aqueous humour. Eye. 1989;3: 463-7.

21. Kusne Y, Kang P, Fintelmann RE. A retrospective analysis of intraocular pressure changes after cataract surgery with the use of prednisolone acetate $1 \%$ versus difluprednate $0.05 \%$. Clin Ophthalmol. 2016;10:2329-36. 
22. Hill JC, Maske R, Watson P. Corticosteroids in corneal graft rejection. Oral versus single pulse therapy. Ophthalmol. 1991;98: 329-33.

23. Vinciguerra P, Albé E, Vinciguerra R, Romano MR, Trazza $\mathrm{S}$, Mastropasqua L, et al. Long-term resolution of immunological graft rejection after a dexamethasone intravitreal implant. Cornea. 2015;34:471-4.

24. Sugar A, Bokosky JE, Meyer RF. A randomized trial of topical corticosteroids in epithelial healing after keratoplasty. Cornea. 1984;3:268-71.

25. Rinne JR, Stulting RD. Current practices in the prevention and treatment of corneal graft rejection. Cornea. 1992;11:326-8.

26. Unal M, Yücel I. Evaluation of topical ciclosporin $0.05 \%$ for prevention of rejection in high-risk corneal grafts. Br J Ophthalmol. 2008;92:1411-4.

27. Price MO, Price FW. Efficacy of topical cyclosporine $0.05 \%$ for prevention of cornea transplant rejection episodes. Ophthalmology. 2006;113:1785-90.

28. Belin MW, Bouchard CS, Frantz S, Chmielinska J. Topical cyclosporine in high-risk corneal transplants. Ophthalmology. 1989;96:1144-50.

29. Shimazaki J, Den S, Omoto M, Satake Y, Shimmura S, Tsubota K. Prospective, randomized study of the efficacy of systemic cyclosporine in high-risk corneal transplantation. Am J Ophthalmol. 2011;152:33-39.

30. Bock F, Matthaei M, Reinhard T, Böhringer D, Christoph J, Ganslandt $\mathrm{T}$, et al. High-dose subconjunctival cyclosporine a implants do not affect corneal neovascularization after high-risk keratoplasty. Ophthalmology. 2014;121:1677-82.

31. Hikita N, Lopez JS, Chan CC, Mochizuki M, Nussenblatt RB, de Smet MD. Use of topical FK506 in a corneal graft rejection model in Lewis rats. Invest Ophthalmol Vis Sci. 1997;38:901-9.

32. Magalhaes OA, Marinho DR, Kwitko S. Topical $0.03 \%$ tacrolimus preventing rejection in high-risk corneal transplantation: a cohort study. Br J Ophthalmol. 2013;97:1395-8.

33. Sloper CML, Powell RJ, Dua HS. Tacrolimus (FK506) in the management of high-risk corneal and limbal grafts. Ophthalmol. 2001;108:1838-44.

34. Vassileva PI, Hergeldzhieva TG. Avastin use in high-risk corneal transplantation. Graefe's Arch Clin Exp Ophthalmol. 2009;247: 1701-6.

35. Dekaris I, Gabrić N, Drača N, Pauk-Gulić M, Miličić N. Threeyear corneal graft survival rate in high-risk cases treated with subconjunctival and topical bevacizumab. Graefe's Arch Clin Exp Ophthalmol. 2015;253:287-94.

36. Bhatti N, Qidwai U, Kazi A. Efficacy of sub-conjunctival and topical bevacizumab in high-risk corneal transplant survival. J Pak Med Assoc. 2013;63:1256-9.

37. Belghmaidi S, Hajji, Ennassiri W, Benhaddou R, Baha Ali T, Moutaouakil A. Managemet of corneal neovascularization prior to corneal transplantation: Reports of 112 cases. J Fr Ophtalmol. 2016;39:515-20.

38. Schmitz K, Hitzer S, Behrens-Baumann W. Immune suppression by combination therapy with basiliximab and cyclosporin in high risk keratoplasty. A pilot study. Ophthalmologe. 2002;99:38-45.

39. Birnbaum F, Böhringer D, Sokolovska Y, Sundmacher R, Reinhard T. Immunosuppression with cyclosporine A and mycophenolate mofetil after penetrating high-risk keratoplasty: a retrospective study. Transplant. 2005;79:964-8.

40. Reis A, Reinhard T, Voiculescu A, Kutkuhn B, Godehardt E, Spelsberg H, et al. Mycophenolate mofetil versus cyclosporin A in high risk keratoplasty patients: a prospectively randomised clinical trial. Br J Ophthalmol. 1999;83:1268-71.

41. Stanojlovic S, Schlickeiser S, Appelt C, Vogt K, Schmitt-Knosalla $\mathrm{I}$, Haase $\mathrm{S}$, et al. Influence of combined treatment of low dose rapamycin and cyclosporin A on corneal allograft survival. Graefes Arch Clin Exp Ophthalmol. 2010;248:1447-56.

42. Chatel MA, Larkin DFP. Sirolimus and mycophenolate as combination prophylaxis in corneal transplant recipients at high rejection risk. Am J Ophthalmol. 2010;150:179-84.

43. Nguyen P, Barte F, Shinada S, Yiu SC. Management of corneal graft rejection a case series report and review of the literature. $\mathrm{J}$ Clin Exp Ophthalmol. 2010;1:100-3.

44. Friedman J, Marcovich AL, Kleinmann G, Schattner A. Low-dose pulsed intravenous cyclophosphamide for severe ocular cicatricial pemphigoid in elderly patients. Cornea. 2014;33:1066-70.

45. Khan IJ, Barry RJ, Amissah-Arthur KN, Carruthers D, Elamanchi SR, Situnayake D, et al. Ten-year experience of pulsed intravenous cyclophosphamide and methylprednisolone protocol (PICM protocol) in severe ocular inflammatory disease. Br J Ophthalmol. 2013;97:1118-22.

46. Park CY, Lee JK, Gore PK, Lim CY, Chuck RS. Keratoplasty in the United States. Ophthalmology. 2015;122:2432-42.

47. Yildiz E, Toklu M, Turan Vural E. Vision-related quality of life before and after deep anterior lamellar keratoplasty. Eye Contact Lens. 2018;44:144-8.

48. Henein C, Nanavaty MA. Systematic review comparing penetrating keratoplasty and deep anterior lamellar keratoplasty for management of keratoconus. Cont Lens Anterior Eye. 2017;40:3-14.

49. Watson SL, Tuft SJ, Dart JKG. Patterns of rejection after deep lamellar keratoplasty. Ophthalmology. 2006;113:556-60.

50. Gonzalez A, Price MO, Feng MT, Lee C, Arbelaez JG, Price FW Jr. Immunologic rejection episodes after deep anterior lamellar keratoplasty: incidence and risk factors. Cornea. 2017;36:1076-82.

51. Roberts HW, Maycock NJ, O'Brart DP. Late stromal rejection in deep anterior lamellar keratoplasty: a case series. Cornea. 2016;35:1179-81.

52. Borderie VM, Guilbert E, Touzeau O, Laroche L. Graft rejection and graft failure after anterior lamellar versus penetrating keratoplasty. Am J Ophthalmol. 2011;151:1024-9.

53. Magalhaes OA, Marafon SB, Ferreira RC. Gender differences in keratoconus keratoplasty: a 25-year study in Southern Brazil and global perspective. Int Ophthalmol. 2018;38:1627-33.

54. Reddy JC, Murthy SI, Vaddavalli PK, Garg P, Ramappa $\mathrm{M}$, Chaurasia S, et al. Clinical outcomes and risk factors for graft failure after deep anterior lamellar keratoplasty and penetrating keratoplasty for macular corneal dystrophy. Cornea. 2015;34:171-6.

55. Kim BZ, Meyer JJ, Brookes NH, Moffatt SL, Twohill HC, Pendergrast DG, et al. New Zealand trends in corneal transplantation over the 25 years 1991-2015. Br J Ophthalmol. 2017;10:834-8.

56. Chan SWS, Yucel Y, Gupta N. New trends in corneal transplants at the University of Toronto. Can J Ophthalmol. 2018;6:580-7.

57. Ang M, Soh Y, Htoon HM, Mehta JS, Tan D. Five-year graft survival comparing descemet stripping automated endothelial keratoplasty and penetrating keratoplasty. Ophthalmol. 2016;123: $1646-52$.

58. Li JY, Terry MA, Goshe J, et al. Graft rejection after Descemet's stripping automated endothelial keratoplasty: graft survival and endothelial cell loss. Ophthalmology. 2012;119:90-94.

59. Jordan CS, Price MO, Trespalacios R, et al. Graft rejection episodes after Descemet stripping with endothelial keratoplasty: part one: clinical signs and symptoms. Br J Ophthalmol. 2009;93: 387-90.

60. Sepsakos L, Shah K, Lindquist TP, et al. Rate of rejection after descemet stripping automated endothelial keratoplasty in fuchs dystrophy: three-year follow-up. Cornea. 2016;35:1537-41.

61. Price MO, Price FW Jr, Kruse FE, et al. Randomized comparison of topical prednisolone acetate $1 \%$ versus fluorometholone $0.1 \%$ in the first year after Descemet membrane endothelial keratoplasty. Cornea. 2014;33:880-6. 
62. Price MO, Feng MT, Scanameo A, et al. Loteprednol etabonate $0.5 \%$ Gel vs. prednisolone acetate $1 \%$ solution after Descemet membrane endothelial keratoplasty: prospective randomized trial. Cornea. 2015;34:853-8.

63. Price MO, Scanameo A, Feng MT, Price FW Jr. Descemet's membrane endothelial keratoplasty: risk of immunologic rejection episodes after discontinuing topical corticosteroids. Ophthalmology. 2016;123:1232-6.

64. Alldredge OC, Krachmer JH. Clinical types of corneal transplant rejection. Their manifestations, frequency, preoperative correlates, and treatment. Arch Ophthalmol. 1981;99:599-604.

65. Hill JC, Maske R, Watson PG. The use of a single pulse of intravenous methylprednisolone in the treatment of corneal graft rejection. A preliminary report. Eye. 1991;5:420-4.

66. Hill JC. Immunosuppression in corneal transplantation. Eye. 1995;9:247-53.

67. Zhao JC, Jin XY. Local therapy of corneal allograft rejection with cyclosporine. Am J Ophthalmol. 1995;119:189-94.

68. Hudde T, Minassian DC, Larkin DF. Randomised controlled trial of corticosteroid regimens in endothelial corneal allograft rejection. Br J Ophthalmol. 1999;83:1348-52.

69. Athanasiadis I, de Wit D, Tsatsos M, Patel AK, Sharma A. Subconjunctival injection of triamcinolone acetonide in the management of corneal graft rejection and new vessels. J Clin Pharm. 2012;52:607-12.

70. Hashemian MN, Latifi G, Ghaffari R, Ghassemi H, ZareiGhanavati M, Mohammadi SF, et al. Topical tacrolimus as adjuvant therapy to corticosteroids in acute endothelial graft rejection after penetrating keratoplasty: a randomized controlled trial. Cornea. 2018;37:307-12.

71. Ghaffari R, Ghassemi H, Zarei-Ghanavati M, Latifi G, Dehghani $\mathrm{S}$, Haq Z, et al. Tacrolimus Eye Drops as Adjunct Therapy in Severe Corneal Endothelial Rejection Refractory to Corticosteroids. Cornea. 2017;10:1195-9.
72. Maris PJ Jr, Correnti AJ, Donnenfeld ED. Intracameral triamcinolone acetonide as treatment for endothelial allograft rejection after penetrating keratoplasty. Cornea. 2008;27:847-50.

73. Reinhard T, Sundmacher R. Adjunctive intracameral application of corticosteroids in patients with endothelial immune reactions after penetrating keratoplasty: a pilot study. Transpl Int. 2002;15: $81-8$.

74. Mayer K, Reinhard T, Reis A, Voiculescu A, Sundmacher R. Synergistic antiherpetic effect of acyclovir and mycophenolate mofetil following keratoplasty in patients with herpetic eye disease: first results of a randomised pilot study. Graefes Arch Clin Exp Ophthalmol. 2003;241:1051-4.

75. Barney NP, Foster CS. A prospective randomized trial of oral acyclovir after penetrating keratoplasty for herpes simplex keratitis. Cornea. 1994;13:232-6.

76. Jansen AF, Rijneveld WJ, Remeijer L, Jansen AF, Rijneveld WJ, Remeijer L, et al. Five-year follow-up on the effect of oral acyclovir after penetrating keratoplasty for herpetic keratitis. Cornea. 2009;28:843-5.

77. Brik D, Dunkel E, Pavan-Langston D. Herpetic keratitis: persistence of viral particles despite topical and systemic antiviral therapy. Report of two cases and review of the literature. Arch Ophthalmol. 1993;111:522-7.

78. Banerjee S, Dick AD. Recent developments in the pharmacological treatment and prevention of corneal graft rejection. Expert Opin Invest Drugs. 2003;12:29-37.

79. Segoloni GP, Quaglia M. New immunosuppressive drugs for prevention and treatment of rejection in renal transplant. J Nephrol. 2006;19:578-86.

80. Tabbara KF. Pharmacologic strategies in the prevention and treatment of corneal transplant rejection. Int Ophthalmol. 2008;28: 223-32.

81. Baradaran-Rafii A, Eslani M, Djalillian AR. Complications of keratolimbal allograft surgery. Cornea. 2013;32:561-6. 